\title{
Applying psychology for design students: reflections and future work
}

\author{
Kellie Morrissey, Niamh Munday, Aidan Kennedy, Maya Brennan \\ University of Limerick \\ *Corresponding author e-mail: kellie.morrissey@ul.ie
}

\begin{abstract}
:
Despite many programmes educating student designers in both human-centred and (increasingly) 'more-than-human' design, the psychology taught to such design students is often truncated, decontextualized, and potentially even harmful if applied without care and sensitivity. Conversely, a more complete reading of psychological theory and literature may help student designers to cultivate their growing practice with regard to ethical conduct and the design of products, services and systems that serve, rather than marginalise, already vulnerable users. This short, reflective paper describes the running of a new module, Psychology for Design, for final year Product Design students. Through annotated examples of student design work, we describe how critical engagement with psychological theory and literature helped students to redesign a series of artefacts in order to imagine them as more accessible, safer, or conducive to health and wellbeing. The paper concludes with a series of short questions which may guide future work in the area.
\end{abstract}

Keywords: applied psychology; design education; individual differences; ethics

\section{Introduction}

Recent calls for change in design education emphasise renewed ethical imperatives as junior designers become increasingly implicated in the creation of products, services and systems which allow - or constrain - better, fairer futures for all (Scherling \& deRosa, 2020). Even in the shift towards 'more- than-human' design (Giaccardi \& Redström, 2020), the design 'things' we create almost always implicate human actors; and therefore, a rich understanding of these human actors is important. However, as noted by Meyer \& Norman (2020), design education rarely delivers this understanding in a systematic manner, meaning that many student designers educated in programmes which promise to teach 'human-centered design' often do not understand the 'human' as well as they may need. Moreover, the psychology taught in such programmes (Leech, 2013; Nodder, 2013) can sometimes privilege the sort of 'design psychology' which we might do better without - e.g., how to appeal to a mass audience, or even how to persuade or addict (Chivukula, Brier, \& Gray, 2021; Gray et al, 2021) - when instead, a richer reading of psychological literature and 
theory might hold important lessons for designers wishing to ameliorate our shared future in a more humanistic manner. In particular, a richer and more critical reading of such literature may help our students to understand how to design for individual differences and intersections of experience in order to highlight the issues which affect those who are underprivileged by the society and systems which designers have, in part, created.

In this short, reflective paper, I will present a new module offered to final year students in the BSC Product Design and Technology (beginning January 2021) in the University of [Blank], Ireland, which took a wide view of psychological theory and literature to offer students an indication of how such a reading of the field could influence their design practice. By presenting three examples of student work, I will offer a brief description of how the students' engaging with psychological literature surrounding 1) gender, 2) sexuality, and 3) neurodiversity led to their redesigning a series of products, services and systems in ways which were more considered, more ethical, and more cognisant both of human failings as well as our potential to do better. I will finish with a short discussion of the benefits and shortcomings of such an education in design psychology, as well as a series of prompts which may guide future work.

Table 1. Topics covered in the module

\begin{tabular}{|c|c|}
\hline Lecture & Topics covered \\
\hline $\begin{array}{l}\text { Psychology: an introduction and } \\
\text { short history }\end{array}$ & $\begin{array}{l}\text { Evidence; scientific method; debates in psychology; } 19^{\text {th }} \text { and } 20^{\text {th }} \text { century schools } \\
\text { of thought }\end{array}$ \\
\hline Ethical principles in psychology & $\begin{array}{l}\text { Ethics and morals; the origins of research ethics; case studies with problematic } \\
\text { ethics; codes of ethics }\end{array}$ \\
\hline Developmental psychology & $\begin{array}{l}\text { Prenatal, newborn \& infant development; cognition in infancy and childhood; } \\
\text { attachment; parenting styles and gender identity; adolescent cognition and } \\
\text { development }\end{array}$ \\
\hline $\begin{array}{l}\text { Sensation, perception, and } \\
\text { consciousness }\end{array}$ & $\begin{array}{l}\text { Basic principles of sensation and perception regarding vision, hearing, touch; an } \\
\text { introduction to consciousness }\end{array}$ \\
\hline $\begin{array}{l}\text { Theories of memory and } \\
\text { attention }\end{array}$ & $\begin{array}{l}\text { The 3-stage model of memory; encoding; storage; retrieval; forgetting; memory as } \\
\text { constructive and cultural; false memories }\end{array}$ \\
\hline Motivation & $\begin{array}{l}\text { Perspectives on motivation; extrinsic and intrinsic motivation; hunger; eating } \\
\text { disorders; the psychology of sex and sexual orientation; social motivations; goal } \\
\text { achievement }\end{array}$ \\
\hline Social thinking and behaviour & $\begin{array}{l}\text { Theories of self; the fundamental attribution error; attitudes; influence; } \\
\text { conformity; deindividuation; behaviour in groups; prosocial behaviour; } \\
\text { stereotyping; social learning theory }\end{array}$ \\
\hline Intelligence & $\begin{array}{l}\text { A brief history of intelligence; psychometric and cognitive approaches; job } \\
\text { performance, longevity, education; The Flynn Effect; brain size; ethnic group and } \\
\text { sex differences }\end{array}$ \\
\hline Personality & $\begin{array}{l}\text { Psychodynamic approaches; neoanalytic \& object relations; adult attachment; } \\
\text { phenomenological-humanistic perspectives; biological perspectives; trait } \\
\text { perspectives; social-cognitive perspectives }\end{array}$ \\
\hline Language and communication & $\begin{array}{l}\text { Properties and structure of language; understanding and producing language; } \\
\text { acquiring a first language; bilingualism; linguistic influences on thinking; dyslexia; } \\
\text { non-verbal communication }\end{array}$ \\
\hline Health, wellbeing and stress & $\begin{array}{l}\text { Stress: stressors, appraisal, adaptation; stress and psychological wellbeing; stress } \\
\text { and physical wellbeing; health promotion and illness prevention; the } \\
\text { transtheoretical model; behaviour \& health maintenance; positive psychology }\end{array}$ \\
\hline
\end{tabular}




\section{About the module}

The module, Psychology for Design, replaced a module in Occupational Psychology which had been service-taught in previous years. As a relatively new hire in the School of Design (beginning late 2019), with a background in Applied Psychology and a history of teaching Human-Computer Interaction in Ireland and the UK, I designed the module to address some of the issues which I had noticed persisting in final year students:

1. Students were unfamiliar with carrying out academic databases searches, and did not have a good understanding of what made certain secondary sources credible (or not);

2. Students were not clear on how to evaluate these sources, and this led to their making claims in their design work which were not backed up by evidence;

3. Finally, although students' design work almost always implicated human actors at some level, the ways in which they wrote about these actors' psychologies or behaviour belied a lack of understanding regarding terms like memory, emotion, perception, motivation, and social behaviour.

It is important to note that despite these brief criticisms, students' design work was, and remains, at a high standard, winning several international prizes, securing them employment, and making a meaningful difference to the communities with whom they work; and indeed, the criticisms I levy here are likely to be similar in many undergraduate programmes (Souleles, 2017).
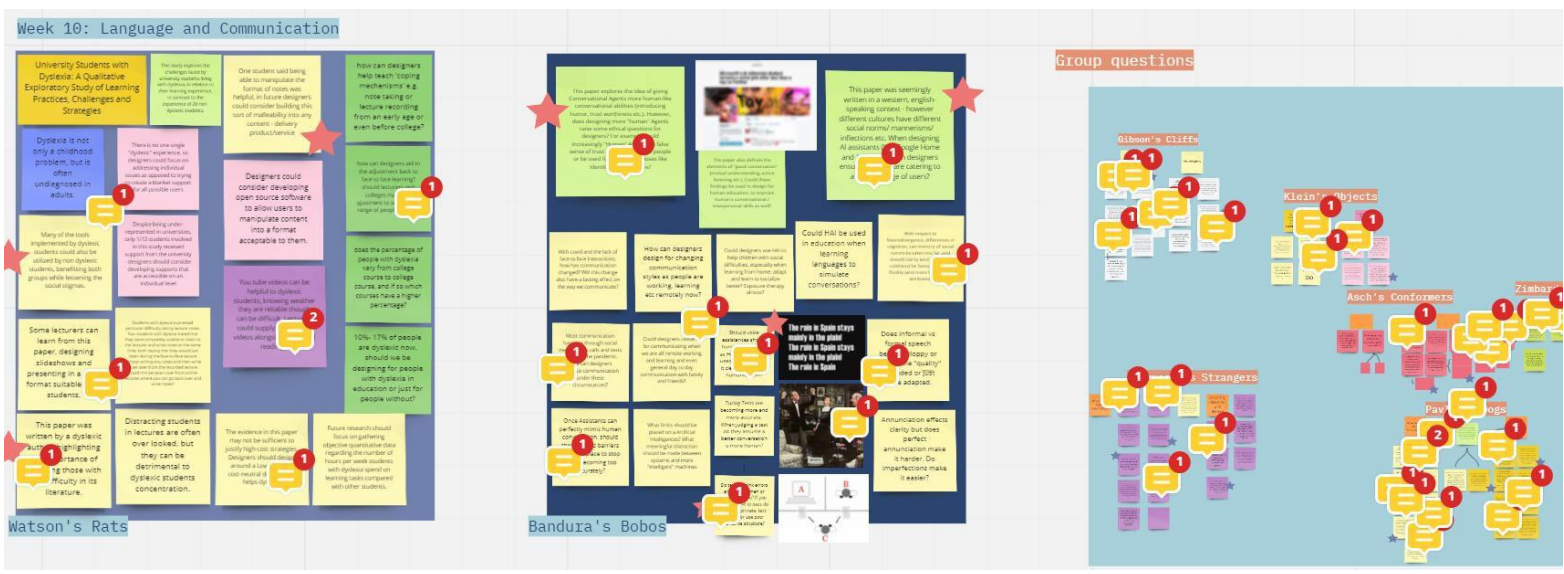

Image 1: A snapshot of students' work on Miro during in-class time

In response to these issues, I proposed the module as a 12-week course, with 6 associated ECTS, which would comprise of twelve 2-hour (online, due to COVID-19) meetings - one hour of lecture, and one hour of group work - focusing on basic psychological theory and literature, but with a strong focus on applying this to design practice. I divided the 38 students up into 12 groups, and each week, all students read 2 assigned papers focusing on the topic for the week. In the second hour of group work, 2 'presenting' teams would rapidly create posters on a Miro board based on the readings for that week, while the 10 remaining teams would come up with questions and comments, both directed at the presenting teams, and for a more general discussion. The final assignment was to redesign a 'thing' a product, service, or system - with psychological theory and literature as a starting point, and to present this work in a process book. To do this, students worked from their own developing personal understanding of psychological studies based on lectures, reading, and groupwork. 
In the next section, I will present three worked examples from students' work and indicate how their enriched understanding of psychological theory led them to redesign their artefact with both complex human actors, and a kinder shared future, in mind.

\section{Exploring students' work}

\subsection{Gender}

Through the course, many students were interested in psychological literature that explored or explained some of the individual and group level differences which they had themselves perceived in their own lives. In particular, the recurring notion of nature vs. nurture and gender socialisation was of interest, as were controversial and contested psychological differences between ethnic groups, and the homogeneity of the populations which much of empirical psychology has built its foundations. One student, Maya, was struck by the discussions around gender socialisation in childhood and its material links to the artefacts with which we present our children, and presented a redesign of the latest Barbie playset (Mattel, 2021).

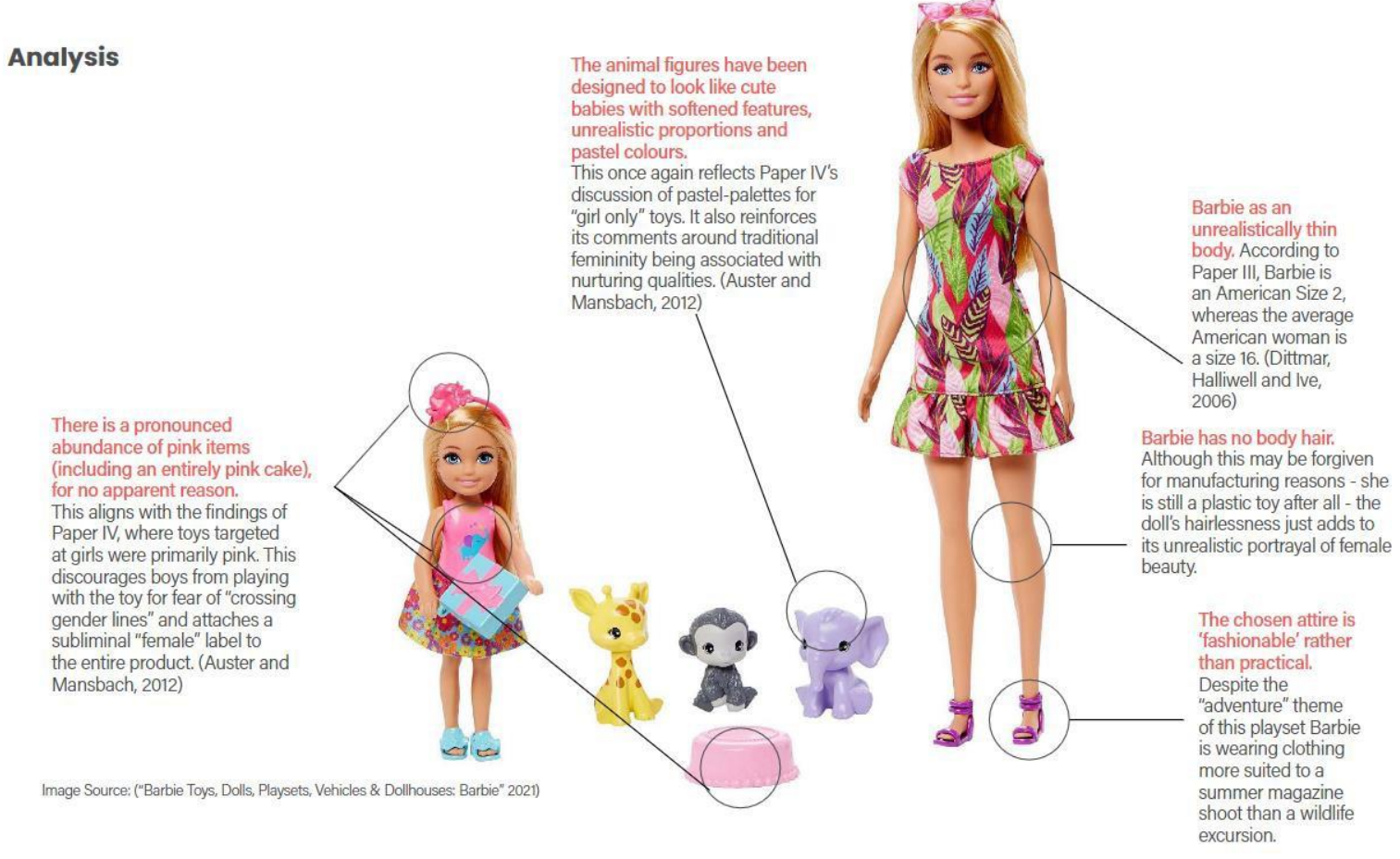

Image 2: Maya's analysis of the Barbie play kit

Maya reviewed five academic papers to ground her design, and from this analysis articulated a design plan rooted in the findings of these papers - 'promote a more diverse and gender neutral set of skill sets among the users'; 'remove [an] unattainable thinness ideal'; to reduce the 'prominence of certain colour palettes... and domestic duties and physical appearance'; and to take on board evidence that 'non-realistic, non-gendered, open-ended toys resulted in the highest quality play'. Maya proceeds from the academic literature to note several features which have been criticised by psychological investigation (Brownell \& Napolitano, 1995) as well as the mass media (Burling, 2016]; the overuse of pink; the unrealistic thinness and pronounced makeup on the dolls; the focus on fashion over practicality (Barbie is supposed to be on a wildlife excursion). However, her analysis also demonstrates some less publicised issues - the promotion of a white beauty ideal (Maya notes that 
the 'classic' white doll is Mattel's most popular despite an attempt at diversity in recent years); the perfect, blemish- and hair-free skin on the doll; and a generally impoverished set of packaging and accessories, which both offer little educational information as well as constrain the site of play.

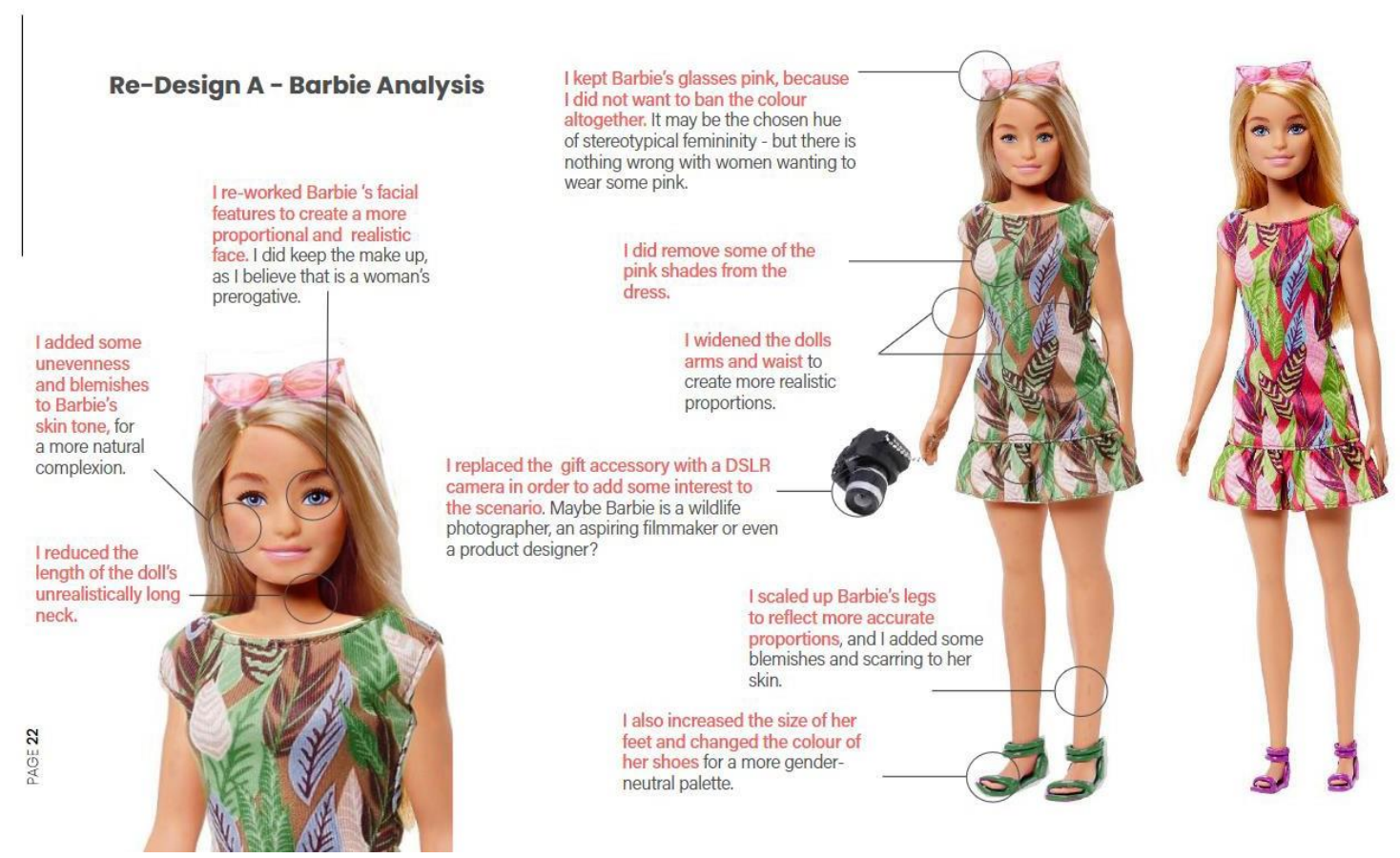

Image 3: Maya's Barbie redesign

In her redesign, Maya focuses on increasing the realism of the doll's physicality: reworking her facial features for proportionality; reducing the length of her neck; scaling up the thickness of her legs; replacing some (but not all) of the pink in her clothing; and giving her a DSLR camera, suggestingthat 'maybe Barbie is a wildlife photographer, an aspiring filmmaker, or even a product designer?' Maya also redesigns the Chelsea doll, as well as the animal accessories, similarly adhering to guidelines laid out by her psychological literature review.

Re-Design B - Analysis

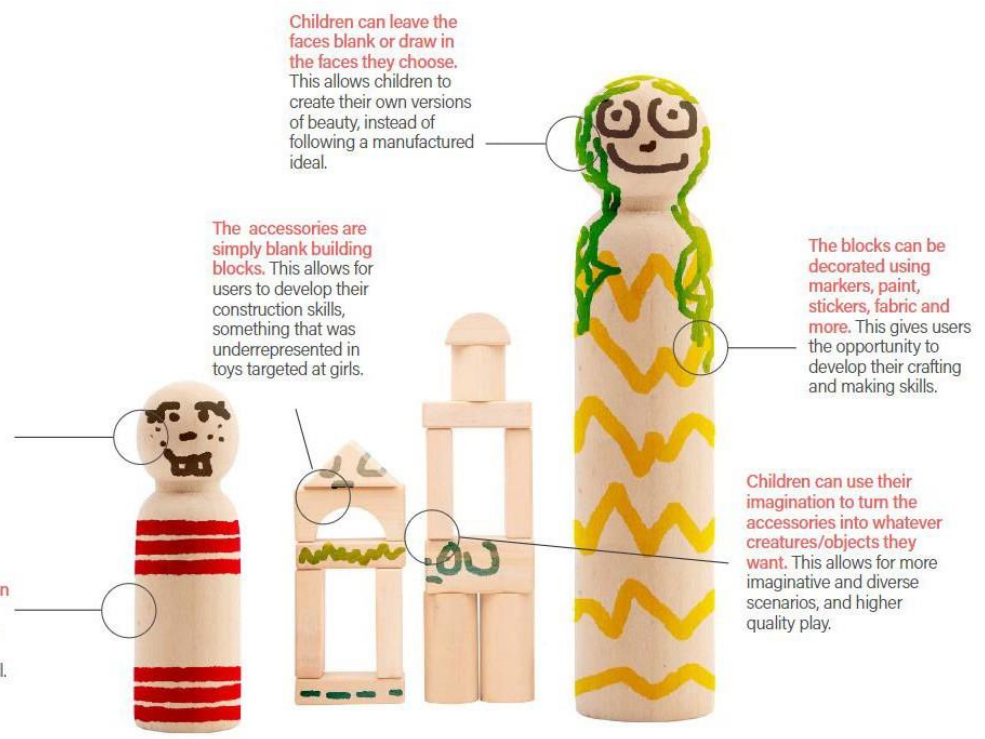

Image 4: Maya's 'open-ended' redesign 
Finally, Maya also includes a brief but radical redesign of the toy in order to make best use of the recommendations from her literature review that open-ended toys result in high-quality play. In this simple redesign, Maya presents a series of wooden figures with associated markers intended for children to use and re-use outside the confines of gender socialisation.

\subsection{Sexuality}

Discussions around nature vs. nurture as well as gender socialisation also often extended to sexuality and sexual preferences. One student, Aidan, focused his redesign on geosocial networking apps, with a focus on the gay hookup app Grindr. Aidan carries out an extensive literature review of such apps, noting that 'these spaces act as important social outlets, however, they are not as socially responsible as they might be, and oftentimes facilitate or even encourage harmful attitudes'.

Proceeding similarly to Maya, above, Aidan reviews a series of academic papers, emerging with an extensive list of 'takeaways', with many high-level contributions such as 'safe spaces such as these apps are crucial for people living in regions where queerness is illegal and/or punishable by death ... it must also be acknowledged that in contexts such as those these platforms could also be used to cause enormous harm to their user bases.

\section{ANALYSIS}

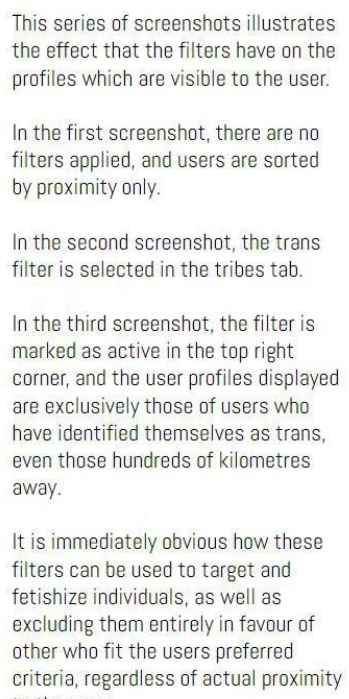

In the second screenshot, the trans filter is selected in the tribes tab.

In the third screenshot, the filter is marked as active in the top right corner, and the user profiles displayed are exclusively those of users who have identified themselves as trans, even those hundreds of kilometres away.

It is immediately obvious how these filters can be used to target and fetishize individuals, as well as excluding them entirely in favour of other who fit the users preferred criteria, regardless of actual proximity to the user.

Image 5: Aidan's analysis of Grindr
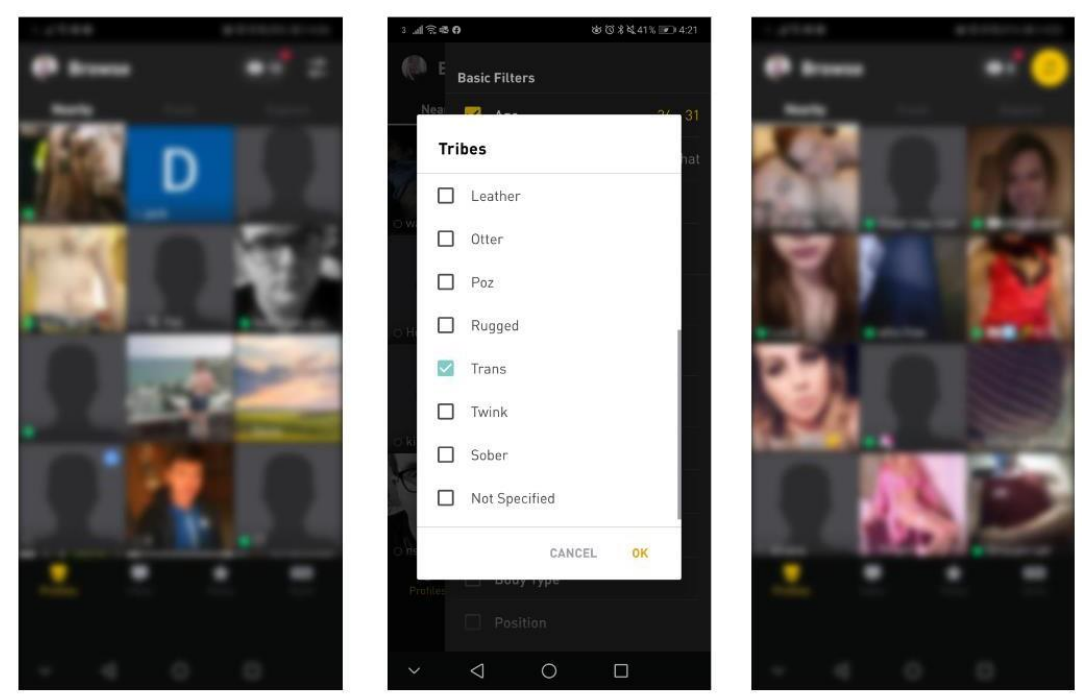

Aidan then presents an analysis of Grindr over several pages; his notes at this stage range from basic annotations surrounding the usability of the $\mathrm{UI}$, to considerations for users' privacy and the sensitivity of the data associated with the app itself. He also notes some issues concerning a lack of representation of asexual identities; masking of age differences; an overemphasis on appearance; and the potential for vulnerable users to be exposed to abuse. He later goes on to emphasise the benefits of the app's existing gender identity features, as well as the usefulness of the sections on sexual health, though he notes that they are somewhat 'buried'. Aidan's redesign of the app focuses on account creation, which he seeks to expand to centre the users' interests; the homepage, which will be redesigned to reduce the possibility of unconsented location of users; the filtering system, to reduce the potential for harassment; and the expansion of safety and health features. In doing this, he clearly links the redesign back to literature reviewed in earlier sections. 


\section{REDESIGN}

Sexual health screen reminders to get tested are now full screen reminders every time the app is opened until the user confirms they have had a test. The role of the reminders has also expanded to act as pathways through which users can register as patients and book appointments with their nearest free clinics. (Miller, 2015)

Users can opt to access their sexual health history, test results etc, as well as details such as patient numbers etc. which can often become misplaced.

These details can be passcode protected due to the sensitive nature. (Hoang et al. 2016)

Users who access the app a certain number of times in a given period will be presented with an informational page/ application form on PrEP. Users will be given an overview of PrEP including relevant statistics, and given the option to fill out a PrEP application for their nearest PrEP clinic. This specific information will be region specific depending on infrastructure available, and in some cases may not be entirely anonymous. (Hoang et al. 2016)

Other sexual health interventions could include rapid HIV test centres such as those on university campuses, information on free condoms/lube available to users via hospitals/clinics/community programs etc. Grindr has been identified as an avenue of significant value in the dissemination of sexual health interventions and the expansion of these interventions stands to impact positively on the sexual health of its user base. (Miller 2015)

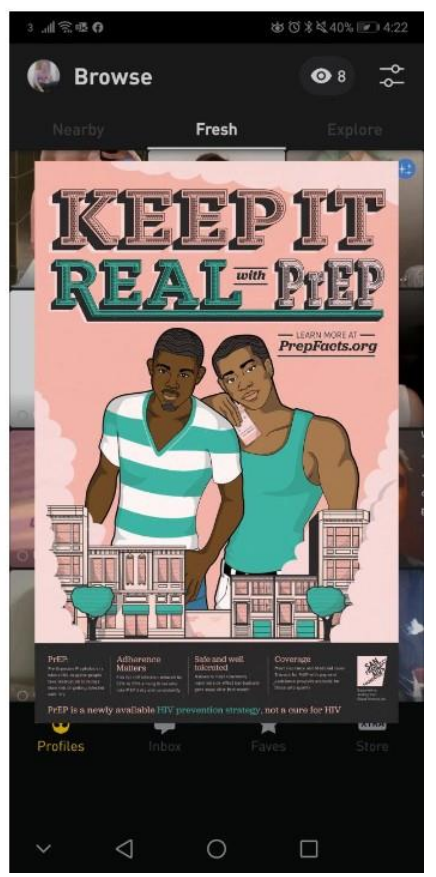

Image 6: Aidan's redesign of the app focuses in part on the expansion of sexual health services

Aidan completes his redesign primarily through simply-modified screenshots of the existing Grindr app as well as a significant amount of text; he also imagines his redesigned Grindr app by speaking about its new or expanded features in the present tense.

\subsection{Neurodiversity}

A recurring topic of interest for many students over the 12-week module was that of neurodiversity, with students raising questions around common symptoms and disorders such as depression, anxiety, autism, dyslexia and ADHD, primarily by asking how designers can better include users with these conditions in the design of products, services and systems. One student, Niamh, centred her redesign around shopping trollies for children with autism spectrum disorders (ASD), proceeding from psychological literature which noted that supermarket shopping often entails 'an overwhelming abundance of sensory stimuli'.

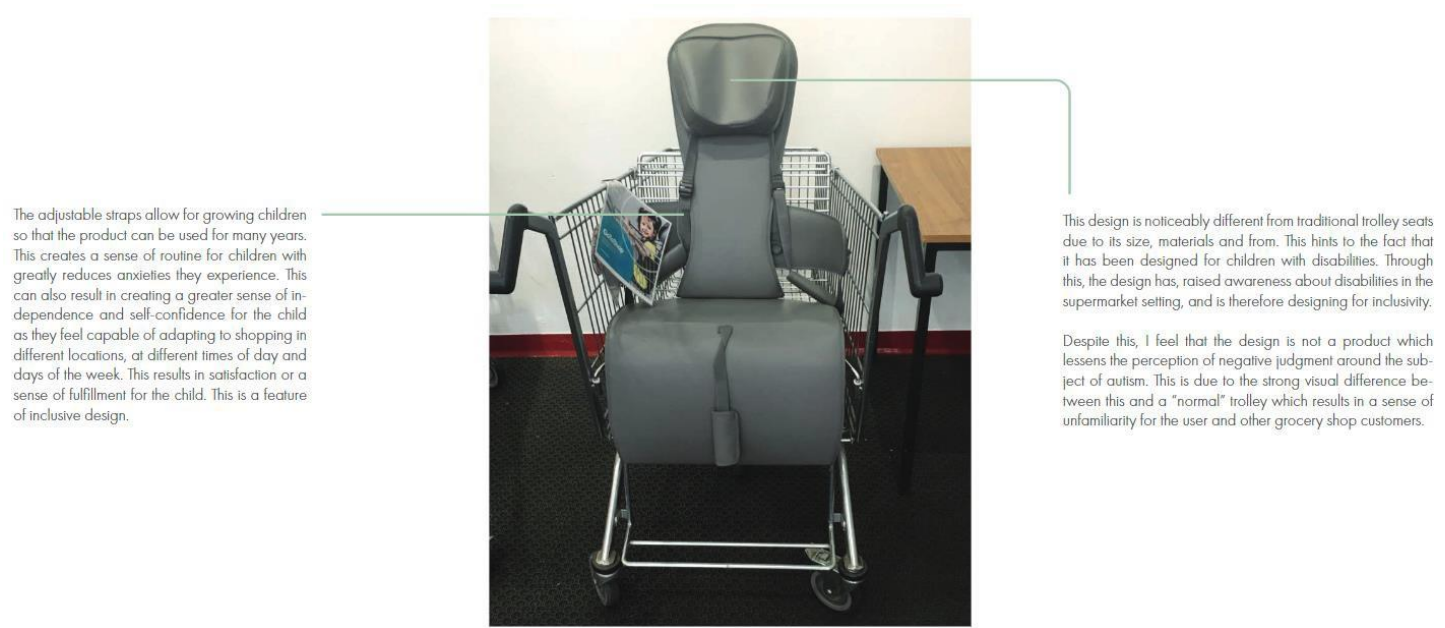

Image 7: Niamh analyses a trolley made for children with ASD 
As before, Niamh began by reviewing several psychological articles surrounding children with ASD. Niamh operationalises her findings from this literature review as a page of questions which go on to guide her design, such as "Can my redesign create a feature/activity/experience which will "trump" the uncomfortable sensory experience of grocery shopping (bright lights, loud music, etc.)?'; or 'How can I use design to reinforce the child's perception of safety within the grocery shop setting?'. She then proceeds by reviewing both standard shopping trollies, trollies designed for seating children with ASD, and a range of products marketed for children with ASD to help with feelings of safety, comfort and security, such as the Ika swing chair (TinkThings, 2021). Her analysis culminates in a summary which draws together several strands of literature and both the benefits and the drawbacks of existing designs, focusing on ameliorating elements like brash, contrasting colours, a sense of overexposure in the open trolley seat, and the sensation of metal on skin.
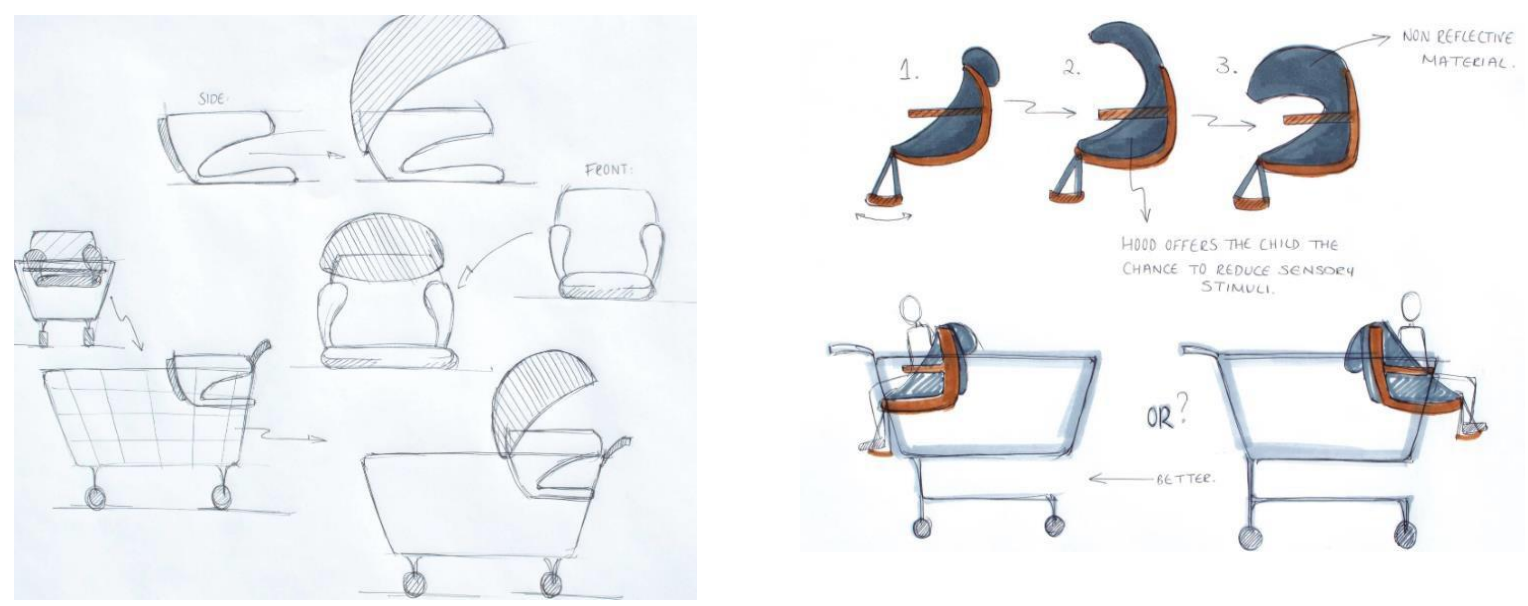

Image 8: sketches from Niamh's ideation process
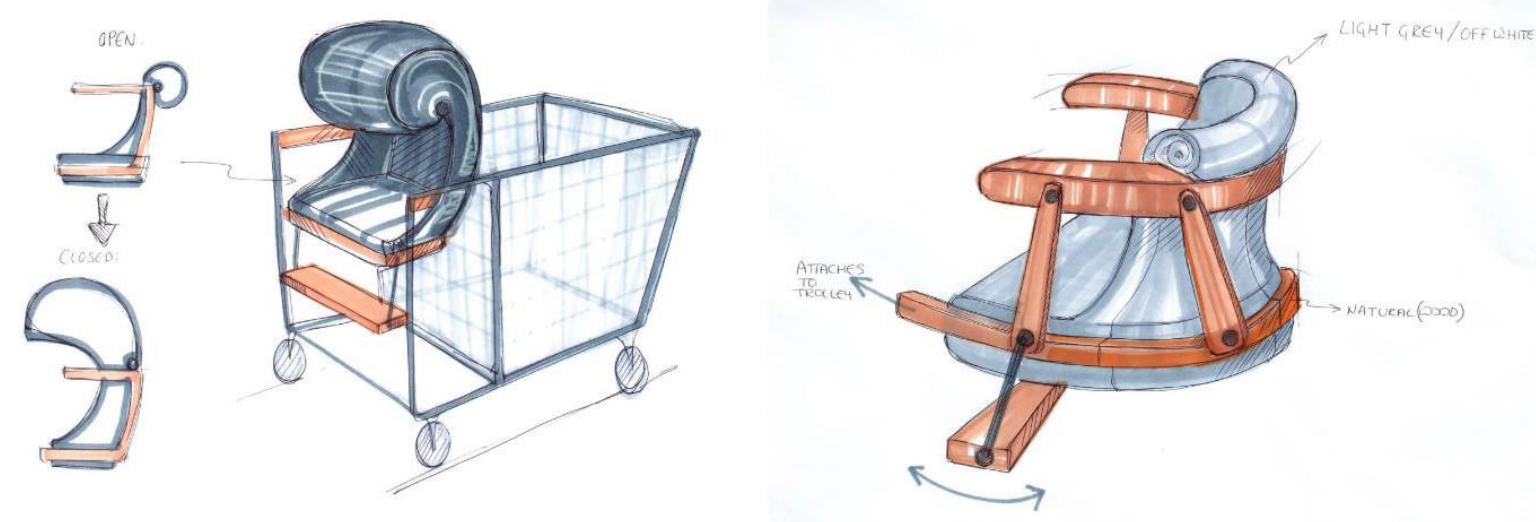

Image 9: Niamh's redesigned trolley seat for children with ASD

Niamh engages in an ideation process to sketch out some possibilities stemming from her research as well as basic psychological principles learned in class. Annotating image 8 , she states that '... bottom-up processing refers to the fact that perceptions are built from sensory input. By addressing the amount of uncomfortable external stimuli that the child is exposed to in the supermarket setting, this product will allow the child to address how they perceive the situation and aids them when using a bottom-up processing approach.' Her final design, in image 9, is 'made of natural, durable and calming materials', and has a matching colour scheme, 'ensuring the design does not cause any uncomfortable sensory experiences for the child', as well as a cocoon hood and removable seat cover - allowing the parent 'to bring their own cover which their child associates with their crystallized 
space at home', and ensuring that 'sitting in the trolley seat becomes a reliable and repeatable routine for the child'.on the field.

\subsection{Student's reflections}

All students wrote a short, personal reflection on their time in the PD4008 module and on their design work, submitted alongside their assignment. Both Niamh and Maya noted that, while they had a 'lay' understanding of their topic beforehand, the module offered them an opportunity as well as the tools to investigate the area more fully - 'I had never researched this issue in depth nor understood it from a psychology standpoint. This was something I really enjoyed and will bring forward in my future projects' (Niamh). Maya notes that the module provided evidence for suspicions she'd already had - 'Although I was already fairly disillusioned with gender stereotyped products - particularly those targeted at women - I was shocked to discover the extent of the issue, especially among children. It was heart breaking to think that the insecurities and challenges we face as women is drilled into us at such a young age.' Aidan similarly notes the interaction of his own personal experience with the way he approached the redesign: 'This project was definitely made easier by my own personal understanding and relationship with the system ... I am however a white able-bodied cisgender male living in a developed country, and so it is entirely possible that some of these [new] features would be difficult, unviable, or harmful to introduce in cultures and contexts which I am not more familiar with.'

\section{Discussion}

In this module, students engaged with lectures on psychology as well as readings of psychological literature in order to redesign products and systems of their choice. As seen in the previous, students were able to apply the literature to motivate redesigns which were not only satisfactory from a usability standpoint, but were in fact enriched or made safer and more conducive to wellbeing. All three students chose to redesign products in order to make them more accessible to 'vulnerable' users, and through their reflections, noted that the module and its assignment offered them a chance to engage with areas of personal interest or concern through a new design lens.

There are clear limitations to this piece of reflective research: as I was unable to review other courses of psychology within design education (indeed, such material is usually not accessible to the public), I do not claim that the course is totally unique (though it appears to be the only such module offered in design education in Ireland). Moreover, as the designs generated by the students were not finished and evaluated formally (outside of grading), I also do not claim that the designs they created have been evaluated rigorously as more accessible or safer according to standardised tests. In future, I will endeavour to teach these students to use such evaluatory models in their own pre- and postassessment of their own work, leaning on their budding education in psychometrics within the course.

Although the module was well-received by students, and the design work often exemplary, the experience also provided me, as a design educator and a psychologist by training, with some new learnings and questions, which I share below as three questions for future work in the area.

How to represent complex interaction simply?

A criticism often levied at psychology education within design is that designers often 'pick and choose' which aspects to teach and apply - e.g., Hicks' Law, Gestalt theory, basic principles of working memory - without teaching the wider context, or how these concepts inter-relate and interact within individual psychology and complex social interaction. In this module, I tried to give a 
wider overview of the area and indicate to design students where more studied theories - e.g., the Transtheoretical Model of Behaviour Change - intersect with areas such as social thinking and motivation so that the wider frame is not lost. However, this still resulted in segmenting the course into discrete 'chunks' or sections of psychological thinking and theory which signals that the areas can be understood separately from one another when this is not the case; and when we use a product or system, it is never just one aspect of our psychology interacting with it.

\section{What methods must our students learn?}

A key motivation for suggesting this module was that it would, in part, teach critical academic skills to designers who must be information literate when leaving university; however, although most would agree designers should be able to parse and apply psychological findings, there is a question regarding how much of the social science methodology undergraduate design students should learn. For instance, although junior designers may be required to carry out simple surveys and quantitative analysis, this is not currently taught in our (second-year) Design Research module; similarly, qualitative skills such as interviewing are not dwelt on, and rather the assumption is that 'anyone can do it'.

\section{Can we ever ensure a social conscience?}

The design work presented in this short paper is evidence of these junior designers' desires to cocreate better, fairer futures for all; however, it is within the context of a discrete final year module where they are left, to a great degree, to pursue their own interests. Although these students are taught ethics in both this module and elsewhere in the course, being taught the principles of something, and even applying it in an assignment such as this, is not the same as having to enact that same ethical sensibility in 'the real world'. Students graduating this year are emerging into a future made uncertain both by COVID-19 and by rapidly changing sociotechnical and economic infrastructures which will likely test this same ethical sensibility rather severely. The answer to the question posed - can we ensure ethical conduct or a social conscience? - is likely no, however, more extensive discussions are needed regarding how we might make ethical design conduct by emerging designers more likely in the future.

\section{References}

Brownell, K. D., \& Napolitano, M. A. (1995). Distorting reality for children: Body size proportions of Barbie and Ken dolls. International Journal of Eating Disorders, 18(3), 295-298.

Burling, S. (2016). Three minutes with Barbie and they wanted to be thinner. The Philadelphia Inquirer. Retrieved 23rd May 2021 from https://bit.ly/3mBA13R.

Chivukula, S. S., Brier, J., \& Gray, C. M. (2018). Dark Intentions or Persuasion? UX Designers' Activation of Stakeholder and User Values. In Proceedings of the 2018 ACM Conference Companion Publication on Designing Interactive Systems (pp. 87-91).

Giaccardi, E., \& Redström, J. (2020). Technology and more-than-human design. Design Issues, 36(4), 33-44.

Gray, C. M., Chivukula, S. S., Melkey, K., \& Manocha, R. (2021._ Understanding "Dark" Design Roles in Computing Education. In Proceedings of the 14th ACM Conference on International Computing Education Research (ICER '21).

Leech, J. (2013). Psychology for designers. mrjoe press.

Mattel. (2021). Barbie $^{\circledR}$ and Chelsea ${ }^{\mathrm{TM}}$ The Lost Birthday ${ }^{\mathrm{TM}}$ Party Fun Playset with Doll \& 2 Animals. Retrieved 23rd May 2021 from: https://bit.ly/2SfnmXg

Meyer, M. W., \& Norman, D. (2020). Changing design education for the 21st century. She Ji: The 
Journal of Design, Economics, and Innovation, 6(1), 13-49.

Nodder, C. (2013). Evil by design: Interaction design to lead us into temptation. John Wiley \& Sons. Scherling, L., \& DeRosa, A. (Eds.). (2020). Ethics in design and communication: Critical perspectives. Bloomsbury Publishing.

Souleles, N. (2017). Design for social change and design education: Social challenges versus teachercentred pedagogies. The Design Journal, 20(sup1), S927-S936.

TinkThings. (2021). Ika swing chair. Retrieved 23rd May 2021 from: https://bit.ly/2UP3dJi.

Author Bios:

Kellie Morrissey, PhD is a Lecturer in Design for Health and Wellbeing at University of Limerick, Ireland. Her work focuses on digital design for women's health and design for care.

Niamh Munday is a recent graduate of the BSc in Product Design and Technology at University of Limerick, where her final design project centred on the design of digital and physical products to combat food waste.

Aidan Kennedy is a recent graduate of the BSc in Product Design and Technology at University of Limerick, where his final design project explored design solutions for workflow and quality of life for soft product creators.

Maya Brennan is a recent graduate of the BSc in Product Design and Technology at University of Limerick, where her final design project centred on creating an emergency shelter that can be easily scaled, customised and repaired on the field. 